\title{
Study on Innovation of Drug Rehabilitation Patterns in Ethnic Minority Regions of China
}

\author{
Yongmei Xia \\ School of Political Science \\ Southwest Jiaotong University \\ Chengdu, 610031, China \\ xiaym11@sina.com
}

\begin{abstract}
Subject to the specific social and historical factors, serious drug problems existed in the ethnic minority regions of China. It is difficult to perform drug rehabilitation tasks there. This paper analyzed the constraints of drug rehabilitation in the ethnic minority regions, and introduced the positive roles of religious belief and traditional culture into the drug rehabilitation. Suggestions are proposed to promote the diversification of drug rehabilitation patterns and improve legislation in the ethnic minority regions.
\end{abstract}

Keywords-ethnic minority regions; religious belief; traditional culture; drug rehabilitation pattern; innovation

\section{INTRODUCTION}

In recent years, along with the issue of "Anti-Drug Law" in China, domestic scholars and researchers began to perform increasing studies on the innovation of the Drug Rehabilitation Pattern (DRP). The related academic achievements fall into three categories: 1) macro researches of DRPs, including comparing DRPs of China with those of other countries, which focus on the construction and improvements of the drug rehabilitation system $[1,2,3]$; 2) a certain research on a specific DRP under an micro view $[4,5,6]$; 3) discussion of DRPs from regional drug issues in [7-10]. Occasionally, discussions about DRPs in ethnic minority regions were presented in the last category of studies, although they lacked of necessary details. Currently, serious drug situation appears in the ethnic minority regions of China, which has caused problems to the drug rehabilitation tasks. Therefore, considering the positive role of religious belief and traditional culture, this paper studies the innovation of DRPs in the ethnic minority regions of China, with the attempt to provide suggestions for drug rehabilitation tasks in those regions.

\section{PURPOSE OF INNOVATION}

\section{A. Staus Quo and Constraints of Drug Rehabilitation Tasks in Ethnic Minority Regions}

In the ethnic minority regions of China, the drug problem is quite serious. For these drug addicts who have experienced repeated alternatives in the selection of drug, the drug rehabilitation could hardly witness pragmatic progress. Firstly, due to the remote location or inconvenient transportation for these ethnic minority areas, the monitoring and the rehabilitation on those drug addicts could be rather complicated, while the drug rehabilitation could not be implemented pragmatically. Furthermore, after the removal of the forced drug rehabilitation, the traceability and following management could not be launched, as a result, the re-arresting rate maintains a high rate. Secondly, in the worse areas suffering from drug, the economic development level is poor including quite a lot of State-level poverty-stricken counties. There are almost 600 State-level poverty-stricken counties in the whole country currently; most are lying in the western area and the ethnic minority areas or the place for the transportation of drug. Due to the influence from economic factors, the office expenses for these areas are quite limited, the investment on drug rehabilitation is also poor, the equipment, facilities etc. in the drug rehabilitation centers are lagging a lot, the drug rehabilitation could hardly witnessed quantitative performance. Thirdly, due to the barrier in languages, difficulty in communication, the qualitative performance in the drug rehabilitation is largely affected. In the ethnic minority area, most drug addicts could not speak Chinese, while the staff from the drug rehabilitation center could hardly communicate with them. In addition, due to the strong ethnic identity existing in these areas, people would behave consistently and collectively, the difficulty and degree of work in the management is reinforced. Finally, one serious consequence from the spread of drug is the infection of AIDS, the infection of AIDS through the intravenous drug has become the major way for the infection and transmission of AIDS in the ethnic minority area in China. A lot of these drug addicts acquired by the drug rehabilitation center are infected by AIDS, the drug rehabilitation centers have to conduct their management through categorization and conduct special treatment for them. While for the simultaneous treatment for rehabilitation and AIDS, tremendous cost would be incurred. These would definitely enlarge the difficulty and burden for the drug rehabilitation tasks.

In the ethnic minority regions in China, drug proliferation as well as the increase of drug addicts comes from the special in-depth social and historical constraints, as follows.

1) Poverty by the natural environment or economic factors: Because of remote areas, simple production structure, lagged economic development and/or difficulty for employment, lots of people in the ethnic minority area 
live a difficult life. When they are offering with huge salary by the drug traffickers, some of them would take the risk. Besides, the area with clear comparison of the rich and the poor, the advanced and lagged life and those core area could well contribute to the spread of drug, drug trade has become a short way towards getting rich and minimizing the wealth gap.

2) Historical reasons: These serious areas for drug used to be the area for drug even before the establishment of the new China. Take Liangshan for example, people would not plant and trade, they could consume drug and regard it to be elegant by exhibiting their being rich through the consumption of opium, as a result, for the Yi nationality, the habit for "wine for everyone, drug for everyone" in the area [11].

3) Geological factors: The south-west China and north-west China are close to the two largest international manufacturing bases, namely, the Golden Triangle in the Southeast Asia and the Golden Crescent in the adjacent of Afghanistan, Pakistan and Iran. The long boundary line and the varied transportation passages have caused tracing problems for the police. Consequently, the import of drug through smuggling or border trafficking is quite prevailing.

4) Educational factors: Lots of citizens in the ethnic minority area have poor education background. Lack of understandings of the damage of drugs and relevant laws and regulations, some ethnic groups even regard the consumption of drugs and trading of drugs as legal actions.

\section{B. Purpose for Innovation of Drug Rehabilitation Patterns in Ethnic Minority Regions}

In China, drug addicts have spread across 31 provinces and autonomous regions since the 1980s. In 1999, the National Narcotics Control Commission presented the most serious drug "six disaster areas" according to the severity of drug situation of provinces, autonomous regions and municipalities, including Yunnan, Sichuan, Guizhou, Guangdong, Guangxi and Gansu. This could well show the severity of drug situation in these areas and the difficulty and complexity in drug rehabilitation tasks. The proper resolution of the difficult problem in the rehabilitation in the ethnic minority area could not only reinforce the stability and solidification in the western China, it could also facilitate the construction of the harmonious society with its overall significance witnessed. The control and reduction of drug addict could serve as an effective method for the narrowing of the drug market, prevention of drug related crimes as well as the maintenance of the social stability.

The innovation of drug rehabilitation patterns that could improve the abstinence rate and downgrade the rate of relapse would become the major issue for the drug rehabilitation works in the ethnic minority regions. Currently, the prohibition and rehabilitation of drugs are mostly conducted by the government, and thus the public organizations and religious groups have limited participation. They could not help enough drug addicts completely and effectively. In the practice, some religious groups and public organizations could play active role in the rehabilitation work in the ethnic minority areas, while the advantage in the performance of rehabilitation could also be reflected. Apparently, the practical influence from the religious belief and traditional culture on the society is dual. It is emergent in the current work in taking full advantage of the positive elements in the religious belief and special culture thus to establish the rehabilitation mechanism with local characters for the resolution for the practical difficulties in the rehabilitation in the ethnic minority regions.

\section{POSITIVE ROLE OF RELIGIOUS BELIEF AND Traditional CULTURE IN DRUG REHABILITATION}

The ethnic minority regions in the southwest China and northwest China, due to the long-term influence under the historical culture and customs, presents strong religious consciousness. For those drug addicts with religious belief, the rehabilitation through religious belief could achieve the performance beyond the reach of the Materialism Education. Furthermore, in the practice, some civil anti-drug organizations in the ethnic minority areas could play an important role in the rehabilitation by taking advantage of religious culture. Meanwhile, a lot of experience has been accumulated.

\section{A. Positive Role of Religious Belief in Drug Rehabilitation}

Introducing religious belief into drug rehabilitation comes from the religious teachings theory. The religious teachings theory was oriented to the redemption in the western religious ethnics which has been applied to the prison by reclaiming those prisoners. Religious teachings is supposed to reclaim and educate the target through the doctrine and teachings activities thus to stimulate the moral repent of these targets and conform to the judgment. The representative of the Criminal Anthropology School Garofalo holds that: despite of the limited functions in the religious education, the scope for effect could be much broader than the normal education; a highly enlightened government should encourage but never stop this moral teachings force and the country could be neutral at most; the elimination of the religious teachings could mean the elimination of the constraints, while the power of the influence could be varied, but it could be far better than the lack of moral constraints [12]. The scope of the social controlling function of religion goes far beyond the moral ethnics, as the constraint of morality comes from the public opinions, while the constraint of religious codes comes from the loyalty of believers exhibited to their target for worship. Lately, some scholars from the Hong Kong, Macao or Taiwan had already conducted research on the relationship between the religious teachings and rehabilitation performance from the perspective of religion. Through experiments, for example, Zhang Jialin from Religion Department of Aletheia University in Taiwan concluded that religion teaching activities are correlated with the rehabilitation effect positively and the rehabilitation effect is correlated with the development of religious groups positively [13]. While Shi Yongdong from the Religion 
Department of the Foguang University in Taiwan, based on the research of Zhang Jialin, conducted further experimental research on the drug rehabilitation through Buddhism cultivating [14].

Under the influence from the above theories, religious belief is mostly encouraged to be used to help the drug rehabilitation in the practice in Hong Kong, Macao, Taiwan and other areas in the world. Generally, the drug rehabilitation patterns varied according to different areas. Most countries and regions mainly apply the "voluntary rehabilitation" pattern including some religion-oriented drug rehabilitation patterns. This pattern would mainly depend on the religious ritual and religious doctrines with complete rehabilitation concept and rules to help drug addict to abandon the addiction to drugs through both biological and psychological ways. In the relatively successful rehabilitation model TC rehabilitation model, the introduction of religious rehabilitation methods could also be witnessed, religious people could be seen among the community members, a range of measures including the pharmaceutical treatment, behavior adjustment, spiritual reclaim, supervision and instruction, criticism and confession etc could all be used to facilitate the rehabilitation, the effect is quite impressive. Besides, as in [15], the Christian drug rehabilitation of the Christian has been implemented in Hong Kong for 40 years as one of the most effective drug rehabilitation pattern recognized by the government.

The trial on drug rehabilitation through religious belief started from the western area in our country, and then it spread to other areas gradually. In those ethnic minority areas and areas with many believers of religions, religion has the dominant and widespread social influence. For example, the Tongxin County in Ningxia would regard the mosques as the propaganda based for drug rehabilitation, the rehabilitation and anti-drug education of nationality characters would be arranged for the gathering for every week by utilizing the reputation of the special religious member Imam among the local Hui People. The Woerzi Speaking tour would be invited to give lectures for drug rehabilitation in all villages or counties included, which has well won the appeal of local Hui people [9]. The Yongjian town ( settlement of Hui people) of the Yi \& Hui autonomous county in Yunnan province has also achieved incredible performance in the propaganda of the danger of drugs and the policies and regulations on rehabilitation through the doctrines in the Alcoran by special religious members in centralized improvement campaign on the drug related crimes [16]. Besides, the $\mathrm{Xi}$ Shuangbanna Administrative Division has also introduced the monasticism in its "anti-drug and AIDS prevention campaign". The mosque in the Shadian District of Yunnan has collaborated with the government department in the drug rehabilitation. The religious groups in Xinjiang, Guangdong have also participated the drug rehabilitation. The Christian rehabilitation pattern has spread to Yunnan through the establishment of Christian rehabilitation instruction stations in Kunming, Dehong and Baoshan successively. The positive role of religious groups in the rehabilitation work has incurred the attention from relevant administration departments. Some regional religious groups have also participated the drug rehabilitation model backed by the Government, such as the Islam association in the Urumchi of Xinjiang has organized religious members to conduct teachings and reclaims for drug addicts in the compulsory drug rehabilitation center of this city, while the Christian Youth Association in Guangzhou has also organized the clergies and relevant people to conduct once or twice teachings in the drug rehabilitation center [17].

\section{B. Positive Role of Traditional Culture in Drug Rehabilitation}

The traditional culture of minorities could well play a supplementary role in the drug rehabilitation works. The traditional culture is the historical treasure for this minority and used to play an important role in the promotion of the social development for minorities. For the inherited traditional culture, it is definitely for the powerful momentum for the control of people's mind and behaviors. For example, the Zhutai Town in the Zhaojue County of Liangshan established the first civil drug rehabilitation association Ergu Civil Anti-drug association in 2001, which won the approval and recognition of Luo Gan. The members of this association are formed by these retired veteran cadres, cadres in the villages or communities or the directors from the family. Every person in charge of the family that could be enrolled as the member of the anti-drug association would be responsible for the drug addict in the family. This drug rehabilitation association could take advantage of the power of traditional culture of the minority comprehensively. Some families of Yi people have also invited civil religious person $\mathrm{Bi}$ Mo to host the religious ritual to propaganda the refusal of drug and valuation of life, besides, the drug addicts was forced to abandon the addiction, while the related family members would be educated widely [18]. The Huri drug rehabilitation pattern established on their family true and customs by the Yi people in Small Liangshan could be rather enlightening and exemplary in the drug rehabilitation in the southwest boundary area and the nationalities in the mountainous area in the central-south peninsula area due to the outstanding performance witnessed in the drug rehabilitation practices. These Yi people have tried to use their old customs and the power of belief and rituals bravely to stimulate the powerful force in combating against the biological addiction of people and improve greatly the successful rate of drug rehabilitation of local people.

To be a pity, the above practices are not prevalent despite of its existence, while comprehensive theoretical study is also absent. As a result, the local legislative or law enforcement departments are still prudent on the practical performance of this drug rehabilitation pattern without adoption and promotion. As in [19], from the perspective of the government, any type of religious activities would be declined, from the perspective of senses, the civil drug rehabilitation activities are rightly what the government may hope and advocate. But due to the reason from the system, the interaction between the government and the families lacks reciprocal trust. We appreciate those existing drug rehabilitation and rehabilitation measures witnessed in the 
domestic or international collaboration. While the practice and actions should also consider some implied forces from cultural resources including the ethnic psychology and identity, civil administration mechanism, traditional organizations, customs and rituals etc rather than just the social problems, then the localized and proper drug rehabilitation and AIDS-prevention activities could be selected.

\section{INNOVATION OF DRUG REHABILITATION IN ETHNIC MINORITY REGIONS}

As stated in the Anti-Drug Law in 2008, the drug rehabilitation tasks should be directed by the government, should assign the responsibilities to relevant departments respectively, and could be participate widely by the public. In the "Drug Rehabilitation Regulations" issued on June 2011, the principles for drug rehabilitation were clarified, namely "people oriented, scientific drug rehabilitation, comprehensive improvement, care and assistance". The establishment of this regulation could provide the guidance for the implementation of localized drug rehabilitation works in the ethnic minority regions of China. The religious belief and traditional culture of minorities play a dual role in the practice in the society. How to take advantage of the positive factors in the facilitation of drug rehabilitation, introduce innovation to the drug rehabilitation pattern would become a key and sensitive issue in the conduct of drug rehabilitation works in the ethnic minority areas. It is desired to seek the integration among the local legislation, the religious belief and the traditional culture, to improve the design of relevant systems, and to provide a larger working space for those civil anti-drug organizations and religious groups under the structure of the constitution and legal regulations. This issue is expected to be solved by the legislatures in the autonomous areas.

\section{A. Promote Diversification of Drug Rehabilitation Patterns in Ethnic Minority Regions}

To solve the difficulties witnessed in the drug rehabilitation work in the ethnic minority areas, apart from the reinforcement in the financial support, the drug rehabilitation system should be more open, and the patriotic and religious groups and civil organizations should be encouraged to join the drug rehabilitation activities. The positive elements in the religious belief and traditional culture in the ethnic minority areas should be used to optimize the forced drug rehabilitation pattern, improve the community drug rehabilitation pattern, and establish new drug rehabilitation patterns. Then the plural drug rehabilitation pattern system could be established in the ethnic minority areas. Meanwhile, the supervision and instruction on drug rehabilitation system should also be reinforced. For example, religious groups could organize religious people to conduct teachings, reclaiming to the drug addicts in the drug rehabilitation center and rehabilitation center periodically. The government should provide support, instruction and supervision of the drug rehabilitation teachings. For the assistance to drug prevention with traditional culture by civil organizations, the government should keep an eye on these activities and value the effect and power of social ritual. Take Liangshan region for example, the Tiger's Day model could be an example, namely the positive elements in the lineage culture should be used to help build the non-drug communities. Besides, the basic principle that any religious activities should be constraint by the legal principles should be implemented consistently. One thing to be clear is that the religions here are these world-wide religions including the Buddhism, Taoism, Islam, Christian and religions of the minorities. Meanwhile, the forms of religious activities should be clear. In the practical operation, the administration sector should conduct strict selection of doctrines and abandon negative information. Besides, the strict limitation should be launched on the applicable objects. The drug addicts should be the people who already have religious belief. The legal protection on the freedom in selection of religious belief should not be breached.

\section{B. Improve Legislation in Ethnic Minority Regions}

The implementation of drug rehabilitation work through religious belief and minority culture should be realized under the instruction of the government within the scope of the constitution and other related laws. These autonomous areas should fully utilize their own legislative powers to improve the laws and regulations about religious affairs and drug rehabilitation based on the practical situation of the area. The local legislature should conduct in-depth investigation and research thus to understand the issues witnessed in the local drug rehabilitation work and analyze the in-depth reason for the conclusion of relevant rules for the final launch of corresponding strategies. Some feasible methods could be upgraded into legal regulations with legal force. For example, in the religious teachings, religious groups should start the trial in the drug rehabilitation centers in the centered area for drug addicts. The further steps could be made after the accumulation of certain experience, and then the local legislature could issue regulations for the patterns. Actually, this procedure could not last long. If the legislation is lagged for a long time, the religious activities in the drug rehabilitation and rehabilitation center could be rather random. Possible conflicts or chaos from the religion could be caused easily, and the effect would be reverse. Apart from the special principles for the local drug rehabilitation work in the autonomous areas determined by the local legislation, plural drug rehabilitation patterns should also be specified. In the anti-drug regulations in the autonomous areas, the detailed rights and obligations including the power of all government departments and the basic functional organizations as well as the corresponding legal obligations should be specified thus to improve the feasibility in the law enforcement.

\section{CONCLUSIONS}

Current available theories in the domain of drug rehabilitation did not satisfy the practical demands in the ethnic minority regions. This paper analyzed the positive roles of religious belief and traditional culture in the drug rehabilitation tasks and proposed innovation idea for drug 
rehabilitation in the ethnic minority regions. It is suggested to promote the diversification of drug rehabilitation patterns and improve legislation in the ethnic minority regions. Future researches of this topic are expected to provide further theoretical supports for this drug rehabilitation field, which could also promote the interdisciplinary development of law, sociology, religious studies and sociology and provide practical suggestions for relevant departments in their drug rehabilitation tasks in the ethnic minority regions of China.

\section{ACKNOWLEDGMENT}

This paper is sponsored by the Special Funds Program of the Fundamental Research Funds for the Central Universities (SWJTU09BR266), and by the Research Funds of the Philosophy and Social Science Planning Project of Sichuan Province (SC11W014).

\section{REFERENCES}

[1] L. Li and W. Huan, "To Compare among the Several Current Rehabilitation Patterns in our Country - Ponder from Promulgation of Suppressing Drug Law," Journal of Henan Judicial Police Vocational College, vol.6, pp. 81-83, February 2008.

[2] H.J. Wang, "Major Challenges and Countermeasures on Drug Treatment since the Implementation of Anti-Drug Law," Journal of Yunnan Police Officer Academy, vol. 78, pp.46-50, January 2010.

[3] H. Fang, "Prohibition of Drug-Taking and Narcotics Control Abroad", Journal of Yunnan Police Officer Academy,vol.78, pp.5159, January 2010.

[4] J.W. Wang, "Problems and Countermeasures of Compulsory Drug Treatment -Take Kunming City as an Example," Journal of Yunnan Police Officer Academy, vol.80, pp.47-51, March 2010.

[5] D. Han, "Community drug Rehaibilition Patterns in Integreted and Multipe Perspective - an Empirical Study in Nanjing," Issues on Juvenile Crimes and Delinquency, pp.29-36, April 2011.

[6] X.H. Xu, "Main Problems and Countermeasures of Therapeutic Community Drug Treatment," Journal of Yunnan Police Officer Academy, vol.85, pp.29-33, February 2011.
[7] L.H. Ma, "Countermeasures against Drug Problems in the Frontier Ethnic Regions - from the Perspective of Building a Harmonious Society," Academic Exploration, pp.109-114, June 2007.

[8] Z. Jin, "Reflections on Drug Rehabilitation in the Process of Constructing a Harmonious Xinjiang," Journal of Xinjiang University (Philosophy, Humanities \& Social Sciences), vol.36, pp.37-40, April 2008.

[9] G.Z. Bai, "Study on Drug Problems in Ethnic Areas under the New Rural Construction Perspective," Henan Agricultural, pp.15-17, December 2011.

[10] Q.Y. Liu and H.C. Zhang, "Improvement of Weaknesses of Frontier Community Drug Rehabilitation," Legal System and Society, pp.192193, February 2012.

[11] L.Y. Ma, "Study on Drug Problem Status, Trends and Countermeasures in Liangshan," Journal of Southwest University for Nationalities (Humanities and Social Science), vol. 21, pp.119-124, August 2000.

[12] R. Garofalo, Criminology, 1st ed., Beijing: China Encyclopedia Press, 1996, pp.135.

[13] J.L. Zhang, "Religius Groups and Religious Teachings in Prison Empirical Analysis of Foguangghan Monitoring Ativities in MinDe Treatment Center," http://www.docin.com/p-48481247.html, 2001.

[14] Y.D. Shi, "Comparative Study on Buddhist Meditation Drug Rehabilitation Cases," New Century Religious Studies, vol. 7(4), 2009.

[15] K.H. Zeng, "Study on Demostic Trial Feasibility from Developmen of Gospel Drug Rehabilitation in Hong Kong," Trans. 2009 National Survey on Drug Abuse Prevention Symposium, 2009.

[16] D.H. Sun, "Practice and Enlightenment of Drug Crimes Campaign in Yongjian of Weishan," Journal of Yunnan Police Officer Academy, vol.33, pp.20-23, March 2000.

[17] J.L. Li and Q. Zhang, "On the positive role of religion on Narcotics," Journal of Guangxi Administrative Cadre Institute of Politics and Law, vol. 27, pp. 103-105, May 2012.

[18] F.L. Cai, "The Yi People's Lineage Meeting and Its Function in Contemporary Liangshan Region," Ethno-National Studies, pp.48-55, January 2008.

[19] K.S. Zhuang, H.L. Yang and X.X. Fu, "Tiger's Day Initiative in the Yi Ethnic Region of Xiaoliangshan," Journal of Guangxi University for Nationalities (Philosophy and Social Sciences Edition), vol.27, pp.38-47, March 2005. 